\title{
EFEKTIFITAS PENGGUNAAN MEDIA VIDEO BERBASIS LINGKUNGAN (MVBL) DALAMMENINGKATKAN PERILAKU POSITIF ANAK TERHADAP LINGKUNGAN
}

\author{
Widowati Anantasari ${ }^{1)}$,Jufri.A.W ${ }^{2)}$, Aos Santoso Hadi.W ${ }^{2)}$ \\ Program Studi Magister pendidikan IPA Program Pascasarjana IPA Universitas Mataram ${ }^{12}$ \\ TK Negeri Pembina Selong ${ }^{1)}$
}

Widowati66@gmail.com, awahabjufri@gmail.com, aos_santosa@yahoo.com

\begin{abstract}
ABSTRAK
Perilaku positif anak terhadap lingkungan merupakan cerminan dari pola tingkah lakuyang positif anak sehari-hariterhadap lingkungan. Kemajuan perkembangan perilaku positif anak terhadap lingkungan dapat diperoleh anak melalui pola pembiasaan perilaku seharihari dan ketauladanan yang ditangkap indera anak dan dirasakan anak dari lingkungan tempat anak berada. Anak perlu memperoleh pengalaman dan belajar membiasakan diri dengan perilaku yang positif agar dapat diterima oleh lingkungannya, disenangi dan tidak melakukan yang merugikan lingkungannya. Pengalaman yang diberikan anak harus dipersiapkan untuk membantu anak dapat berbagi, bekerjasama, menghormati, menyayangi, bertanggung jawab dan percaya diri. Penelitian ini bertujuan untuk mengetahui: perbedaan perilaku positif anak terhadap lingkungan pada anak yang belajar dengan menggunakan Media Video Berbasis Lingkungan (MVBL) dengan anak yang belajar tidak menggunakan Media Video Berbasis Lingkungan (MVBL). Penelitian ini adalah penelitian eksperimen semu (Quasi eksperiment) menggunakan pretest-posttest control group design. Data perilaku positif anak terhadap lingkungan diperoleh dengan menggunakan pedoman observasi (pengamatan perkembangan perilaku anak). Data penelitian dianalisis menggunakan tehnik analisis uji-t (independent sample $t$ test). Hasil analisis data disimpulkan bahwa : dengan $\mathrm{df}=16$ pada taraf signifikan 0.05 menunjukkan terdapat perbedaan perilaku positif anak yang belajarmenggunakan MVBL dan anak yang belajar tidak menggunakan MVBL $(t=3,120)$.
\end{abstract}

Kata kunci : MVBL, Perilaku positif terhadap lingkungan

\begin{abstract}
The positive attitude of students toward environment is the manifestation of a positive attitude of students toward the environment. The development of student positive attitude toward environment can be gotten through the aplication of daily attitude and the model that student s catch and feel from the environment where student s live. The students need to get the experiences and learn by themselves with a possitive attitude in order that they are accepted by the environment and they do not do harm their environment. The experiences given to the student should be prepared to help them to share, cooperate, respect, love renponsible, and having self confidance. This research aim at knowing the difference of children's possitive attitude toward environment at students who lern by using video media based environment (VMBE). Will those who do not learn by using video media based environment (VMBE). Research was aquasi experimental research with pretest and posttest control design. The data of students positive attitude toward environment were gotten by using observation technique (the
\end{abstract}


observation of students positive attitude improvement ) The data of this research were analyzed by using the analysis of independent sample t-test tecnique.The result of analysis can be concluded as follows : with $d f: 16$ at significant level 0.05 showed that there was difference of students possitive attitude who learn by using $M V B L$ than those who did not learn by using MVBL $(t=3.120)$

Keywords : VMBE, Possitive attitude toward environment.

\section{Pendahuluan}

Perilaku adalah respon individu terhadap suatu stimulus atau suatu tindakan yang dapat diamati dan mempunyai frekuensi spesifik, durasi dan tujuan baik disadari maupun tidak. Perilaku merupakan kumpulan berbagai faktor yang saling berinteraksi. Sering tidak disadari bahwa interaksi tersebut amat kompleks sehingga kadang-kadang tidak sempat memikirkan penyebab anak menerapkan perilaku tertentu. Karena itu amat penting untuk dapat menelaah alasan dibalik perilaku individu anak. Harlen (Sjarkawi, 2006: 35) mengemukakan bahwa :" perilaku merupakan kesiapan atau kecenderungan seseorang untuk bertindak dalam menghadapi suatu objek atau situasi tertentu”.

Pergaulan sehari-hari, dapat ditemukan dua perilaku, yaitu perilaku positif dan perilaku negatif. Anak yang memiliki perilaku negatif umumnya perilakunya tidak menyenangkan dan membuat anak lain atau orang disekitarnya merasa tidak betah bersamanya. Ia cenderung merugikan anak lain. Sebaliknya anak yang memiliki perilaku positif umumnya kehadirannya didambakan, menyenangkan, dan teman atau orang merasa betah bersamanya. Kehadirannya cenderung menguntungkan berbagai pihak. Perilaku positif mendukung hidup bersamanya.

Anak dalam kehidupan dan pergaulannya sehari-hari mendapatkan pengalaman, pola asuh, pembiasan perilaku dari keluarga dan lingkungan anak. Pola pembiasaan perilaku yang ada dilingkungan merupakan warna perilaku yang akan ada pada diri anak. Anak seharusnya mendapatkan pengalaman dan pembelajaran pola perilaku positif dari lingkungn anak, baik dari keluarga dan orang yang ada disekitar anak. Penerimaan akan diri anak yang baik oleh lingkungan akan membatu anak dapat beradaptasi dengan baik, kepandaian anak beradaptasi dengan lingkungan membantu anak dapat tumbuh dan berkembang dengan baik. Hal ini sesuai dengan UU RI No. 20 Tahun 2003 tentang Sistim Pendidikan Nasional pasal 1 ayat 14 menyatakan bahwa: "Pendidikan Anak Usia Dini (PAUD) adalah ditujukan kepada anak sejak lahir sampai dengan usia 6 tahun yang dilakukan melalui pemberian rangsangan pendidikan untuk membantu pertumbuhan dan 
perkembangan jasmani dan rohani yang meliputi moral dan nilai-nilai agama, sosial emosional, kognitif, bahasa, fisik/ motorik, kemandirian agar anak memiliki kesiapan dalam memasuki pendidikan dasar". Proses terbentuknya perilaku positif anak sangat dipengaruhi pola asuh dan lingkungan tempat tinggal dan tempat anak belajar.

Rendahnya kemampuan anak dalam beradaptasi dengan lingkungan dan apresiasi yang rendah akan ciptaan Tuhan yang ada pada diri anak, akan mempengaruhi sikap dan perilaku anak terhadap lingkungannya. Beberapa sikap bisa muncul pada anak seperti : kurangnya rasa bersyukur terhadap apa yang dimilikinya dan apa yang ada di lingkungannya, berbuat semaunya, kurang mengenal beberapa ciptaan Tuhan di lingkungan, kurang berbagi dengan lingkungannya, tidak memahami manfaat dan bahaya dari benda-benda atau kejadian-kejadian yang ada disekitar sehingga tidak dapat bersikap yang dapat menguntungkan dirinya, tidak mengenali beberapa peristiwa serta obyek-obyek yang dapat membahayakan diri anak, sehingga anak tidak dapat menolong dan menjaga dirinya dari benda-benda yang membahayakan dirinya.

Dari hasil pengamatan awal peneliti, pola pembiasan perilaku positif anak TK Negeri Pembina Selong pada kelompok B belum dapat memberikan pengalaman dan pembiasaan pola perilaku positif yang efektif untuk tertanam menjadi pola tingkah laku anak keseharian. Anak belum dapat berinteraksi dengan ciptaan Tuhan yang ada di lingkungan sekolah, sehingga anak belum dapat berperilaku positif .

Penelitian ini bertujuan untuk melihat perbedaan perilaku positif anak yang belajar dengan MVBL dan anak yang belajar tidak menggunakan media video berbasis lingkungan (MVBL) pada anak kelompok B TK Negeri Pembina Selong kabupaten Lombok Timur.

\section{Metode}

Penelitian ini menggunakan rancangan penelitin eksperimental semu (quasi experiment) karena kontrol yang dipergunakan tidak berfungsi sepenuhnya mengontrol variabel luar yang mempengaruhi pelaksanaan eksperimen (Sugiyono, 2010). Desain yang dipergunakan adalah pre test-post test control group design. Penelitian ini memberikan perlakuan media video berbasis lingkungan (MVBL) yang dikembangkan peneliti pada kelompok eksperimen dan perlakuan dengan media lain (Campuran antara media miniatur ayam dan gambar-gambar) pada kelompok kontrol, untuk mengetahui perbedaan perilaku 
positif anak terhadap lingkungan pada kedua kelompok. Media video dikembangan berisikan pengenalan binatang yang ada dilingkungan anak, binatang Ayam.

Lokasi penelitian ini adalah TK Negeri Pembina Selong kabupaten Lombok Timur, dengan populasi seluruh anak murid di TK Negeri Pembina Selong tahun Pembelajaran 2013/2014 sebanyak 4 kelompok. Sampel penelitian ini diambil 2 kelas sesuai kebutuhan penelitian dengan peetimbangan memiliki ciri, sifat dan umur yang setara yakni : anak kelompok B1 dan anak kelompok B2.

Desain penelitian ini, menggunakan rancangan Control-Group pre-tes post-test Design (Sugiyono, 2010) yang digambarkan sebagai berikut:

\begin{tabular}{|c|c|c|c|}
\hline R1 & $\mathrm{T}_{1}$ & $\mathrm{X} 1$ & $\mathrm{~T}_{2}$ \\
\hline $\mathrm{R} 2$ & $\mathrm{~T}_{3}$ & - & $\mathrm{T}_{4}$ \\
\hline
\end{tabular}

Rancangan penelitian Control-Group pre-test post-test Design

Keterangan :

R1 : Sampel diambil acak untuk kelompok eksperimen

R2 : Sampel diambil acak untuk kelompok kontrol

$\mathrm{T}_{1} \quad$ : Tes awal sebelum diberi perlakuan MVBL

$\mathrm{T}_{2} \quad$ : Tes akhir setelah diberi perlakuan MVBL

X1 Perlakuan dengan media MVBL

$\mathrm{T}_{3}$ : Tes awal kelompok kontrol (tidak ada perlakuan MVBL)

$\mathrm{T}_{4}:$ Tes akhir kelompok kontrol tidak ada perlakuan MVBL

\section{Analisi Data}

Untuk melihat efektifitas media video berbasis lingkungan terhadap perkembangan perilaku positif anak data dilihat dari peningkatan yang terjadi sebelum dan sesudah pembelajaran dihitung dengan rumus $\mathrm{g}$ faktor (N-Gain) dengan rumus Meltzer(2002) (dalam American Journal of Physics (Online), 2002):

$$
g=\frac{\text { Skor Post Test-Skor Pre Test }}{\text { Skor Ideal-Skor Pre Test }}
$$

Keterangan :

$$
\begin{array}{ll}
\mathrm{S}_{\text {post }} & =\text { Skor Post } \\
\mathrm{S}_{\text {pre }} & = \\
& \text { Sest } \\
& \text { Skor Pre test }
\end{array}
$$

Gain yang dinormalisasikan ini diinterpretasikan untuk menyatakan peningkatan perilaku positif anak TK. Adapun kriteria rendah, sedang dan tinggi mengacu pada Meltzer(2002) (dalam American Journal of Physics (Online), 2002) seperti berikut: 
Kategori Tingkat Gain yang Dinormalisasi

\begin{tabular}{cc}
\hline Batasan & Kategori \\
\hline $\mathrm{g}>0.7$ & Tinggi \\
$0.3 \leq \mathrm{g} \leq 0.7$ & Sedang \\
$\mathrm{g}>0.3$ & Rendah \\
\hline
\end{tabular}

Hipotesis yang akan diuji dalam penelitian ini berkaitan dengan ada tidaknya perbedaan perilaku positif anak yang belajar dengan menggunakan MBVL. Tehnik statistik yang digunakan untuk menguji hipotesis adalah statistik parametrik yaitu uji-t sampel independen dengan rumus :

$$
t=\frac{\bar{x}_{1}-\bar{x}_{2}}{\sqrt{\left(s_{1}^{2} / n_{1}\right)+\left(s_{2}^{2} / n_{2}\right)}}
$$

\section{Hasil Penelitian}

\section{A. Deskripsi Perilaku positif anak}

Data yang didapat dari penelitian adalah data pengamatan awal perilaku positif dan data pengamatan akhir pada kelompok kontrol dan kelompok eksperimen. Skor rata-rata nilai perilaku positif kelompok kontrol dan kelompok eksperimen menunjukkan peningkatan. Peningkatan skor rata-rata nilai perilaku positif pada kelompok eksperimen dan kelompok kontrol seperti Gambar 1dibawah ini:

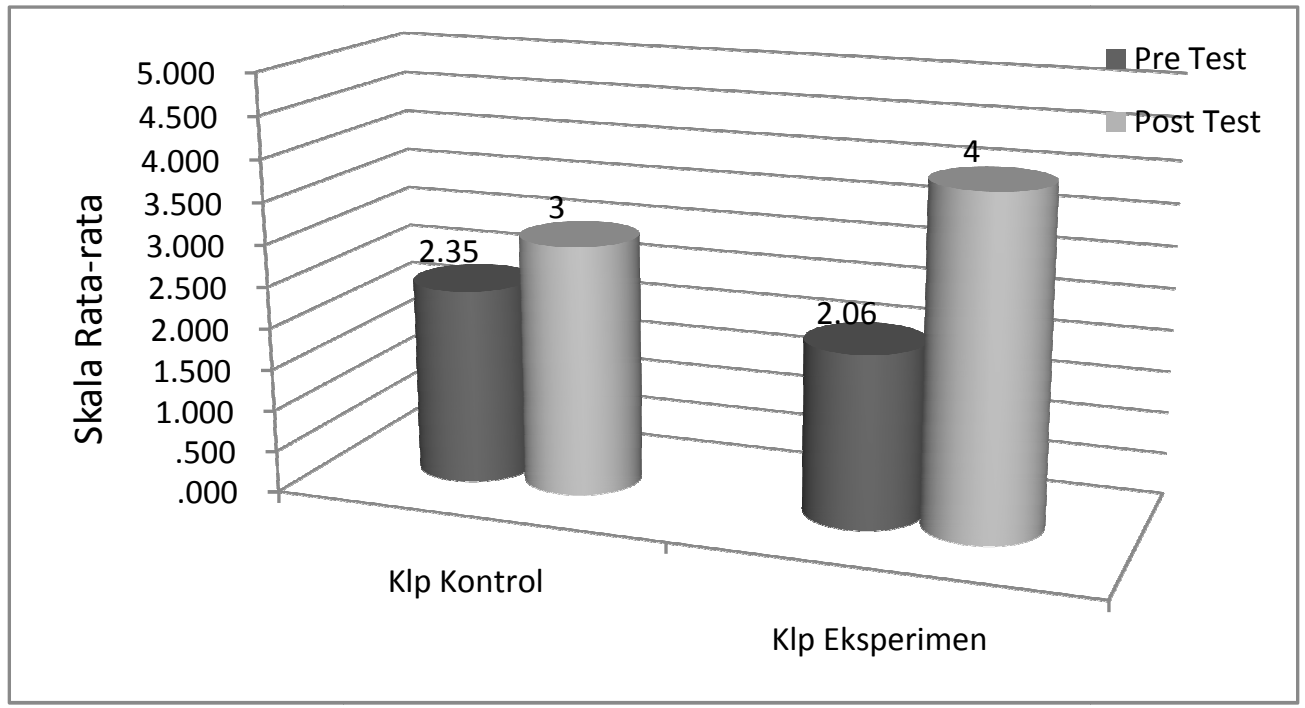

Gambar 1 : Peningkatan skor rata-rata nilai perilaku positif pada kelompok eksperimendan kelompok kontrol 


\section{B. Hasil Uji Hipotesis}

Uji normalitas data telah dilakukan menggunakan uji lilliefors padataraf signifikan $5 \%(a=0,05)$. Uji normalitas data perilaku positif anak menunjukkan pada data kelompok kontrol $L_{\text {hitung }}$ sebesar 0,2058 lebih kecil dari nilai $L_{\text {tabel }}$ sebesar 0,206 dan data kelompok eksperimen $L_{\text {hitung }}$ sebesar 0,1878 lebih kecil dari $L_{\text {tabel }}$ sebesar 0,206 lebih kecil dari $L_{\text {tabel }}$. Maka dapat disimpulkan data kemampuan dasar kognitif kedua kelompok berdistribusi normal.

Uji homogenitas data perilaku positif anak menggunakan uji $\mathrm{F}$ dengan kriteria pengujian jika hasil $F_{\text {hitung }}<F_{\text {tabel }}(\mathrm{a}=0,05)$ maka data tersebut homogen, tapi jika $F_{\text {hitung }}>F_{\text {tabel }}(\mathrm{a}=0,05)$ maka data tersebut tidak homogen. Hasil uji homogenitas diperoleh nilai $F_{\text {hitung }}(1,8096)<F_{\text {tabel }}(2,23)(\mathrm{dk} 16,16$ dan $\mathrm{a}=0,05)$, dengan demikian dapat disimpulkan bahwa data perilaku positif anak kedua kelompok penelitian adalah homogen.

Uji hipotesis penelitian ini dilakukan dengan menggunakan uji perbedaan (komparatif) dengan menggunakan uji-t. Hasil uji statistik uji beda perilaku positif anak diketahui $t_{\text {hitung }}(3,120)>t_{\text {tabel }}(1,746)$ dengan dk 16 pada taraf signifikansi $\mathrm{a}=0,05$. maka Ho ditolak dan Ha diterima ditolak artinya terdapat perbedaan yang signifikan perilaku positif antara anak yang belajar dengan media video berbasis lingkungan (MVBL) dan anak yang tidak belajar dengan media video berbasis lingkungan (MVBL).

Hasil uji hipotesis diperkuat dengan analisisperhitungan $N$-GAIN perilaku positif. Hasil perhitungan $\mathrm{N}$-Gain perilaku positif, diperoleh nilai $G$-Nain kelompok kontrol 0,28 pada ketegori sedang dan nilai G-Nain kelompok eksperimen 0,66pada kategori tinggi. Maka Gain kelompok eksperimen lebih tinggi dari Gain kelompok kontrol, artinya Media Video Berbasis Lingkungan (MVBL) lebih efektif meningkatkan perilaku positif anak dibanding dengan media lain yang digunakan pada kelompok kontrol.

\section{Pembahasan}

Hasil analisis data perilaku positif anak diperoleh $\mathbf{t}_{\text {hitung }}$ sebesar 3,120 lebih besar dari $\mathbf{t}_{\text {tabel }}$ sebesar 1,746 pada dk 16 taraf signifikan 0,05(1-tailed), maka hipotesis ditolak artinya terdapat perbedaan perilaku positif anak antar kelompok yang belajar dengan MVBL dan kelompok yang belajar menggunakan media lain. Dengan menggunakan media MVBL dalam pembelajaran membuktikan bahwa terdapat perbedaan peningkatan perkembangan perilaku positif anak terhadap lingkungan, ini artinya MVBLsignifikan 
efektif dalam meningkatkan perkembangan perilaku positif anak terhadap lingkungan pada kelompok eksperimen dibanding dengan kelompok kontrol.

Denganpembelajaran menggunakan MVBL, anak mendapatkan pengalaman belajar untuk lebih memahami manfaat ciptaan Tuhan bagi kehidupan, diri dan keluarganya. Pengetahuan dan pengalaman belajar tentang ayam yang dimiliki anak ternyata membuat anak berproses untuk lebih peduli terhadap binatang ciptaan Tuhan yang ada di lingkungan mereka terutama ayam. Anak mulai memahami untuk bisa mendapatkan telur dan makan ayam goreng,mereka mulai rajin memberikan makanan bagi ayam peliharaannya dan menjaga anak-anak ayam untuk tetap sehat dan cepat besar, mereka sudah tidak lagi mengganggu anak ayam dan rajin ikut serta membersihkan kadang ayam.

Dengan kepedulian anak terhadap ayam-ayamnya, berarti peduli akan binatang ciptaan Tuhan dengan tidak merusaknya tetapi menyayangi dan memeliharanya dengan baik. Perubahan dan perkembangan perilaku positif anak membuktikan adanya rangkaian dari peningkatan kemampuan dasar kognitif dan keinginan dalam diri anak dalam memperlakukan objek ayam yang ada disekitar mereka, hal ini seperti yang dikatakan Azwar (2009:5) bahwa perilaku positif merupakan konstelasi kognitif,afektif dan konatif yang saling berinteraksi didalam memahami, merasakan dan berperilaku peduli dalam menjaga dan mempertahankan kualitas dan kelestarian objek yang ada di lingkungannya. Demikian pula dengan pengalaman belajar dalam membentuk perilaku diperkuat oleh Bloom (Supratika,2010:3) bahwa, sebagian besar pengetahuan manusia diperoleh melalui mata dan telinga. Pengetahuan atau kognitif merupakan domain yang sangat penting dalam membentuk tindakan/perilaku seseorang.

Secara keseluruhan terjadi peningkatan pemahaman/ kognitif anak yang terbangun melalui pengalaman belajarnya merubah pola perilaku anak untuk peduli terhadap lingkungannya dari lingkungan yang ada di rumah ataupun sekolahnya. Hal ini dikuatkan oleh Kartika(2011), penelitian tentang perilaku anak peduli lingkungan tercermin dalam tingkah lakunya dalam memperlakukan lingkungan, dimulai dari lingkungan yang lingkupnya lebih kecil rumah dan sekolah.

\section{Kesimpulan}

Berdasarkan hasil penelitian, dapat disimpulkan, terdapat perbedaan perkembangan perilaku positif anaksecarasignifikanantarakelompokanak yang belajardengan MVBL dengananak yang tidakbelajardengan MVBL. Peningkatan perilaku positif anak yang 
belajar dengan menggunakan MVBL lebih tinggi dibanding dengan anak yang tidak belajar dengan menggunakan MVBL. MVBL efektif digunakan untuk meningkatkan perkembangan perilaku positif anak.

\section{DAFTAR PUSTAKA}

Sjarkawi, 2006. Pembentukan Kepribadian Anak. Bumi Aksara: Jakarta

Azwar.2009.Penyusunan Skala Psikologi.Yogyakarta:Pustaka Pelajar

Kartika,Rika.2011.Kontribusi Hasil Pembelajaran Geografi Terhadap Perilaku Siswa Peduli Lingkungan.Skripsi:Universitas Pendidikan Indonesia

Meltzer,D.E. (2002), The Relationship between Mathematics Preparation and Conceptual Learning Gain in Physics: A Possible "Hidden Variable" in Diagnostics Pretest Scores. American Journal of Physics (Online). Tersedia: http://www. Physics iastate.edu/per/docs/AJP- Dec-2002-Vo.70-1259-1268,pdf. diakses tanggal 20 juli 2014.

Sugiyono. 2010. Metode Penelitian Kuantitatif, Kualitatif dan $R \&$ D.Bandung: Alfabeta.

Supratika,Resi.2010.Pengaruh Tingkat Kecerdasan (Intelegenci) Siswa Terhadap PembentukanSikap TanggungJawab (Responsibility) dan Partisipasi Sosial (Social Participation). (Studi Komparatif Siswa Akselerasi dan Non Akselerasi/ Reguler di kelas VII SMPN I Sukabumi).Skripsi.FPIPS UPI Bandung.

Undang-Undang Republik Indonesia No.20 Tentang Sistem Pendidikan Nasional. 2003.Bandung: Fermana 